\title{
Entrevista a Marcela Trujillo
}

En esta entrevista, la artista gráfica chilena Marcela Trujillo describe su trayectoria personal como dibujante, destacando su pasión por la pintura figurativa, así como la influencia del cómic underground norteamericano autobiográfico de autoría femenina en su formación artística. Al trazar un breve panorama de la narrativa gráfica latinoamericana actual, resalta la presencia de un número creciente de autoras empeñadas en una renovación de este ámbito de creación artística. En diálogo con Marina Bettaglio, Marcela Trujillo describe los aspectos más innovadores del trabajo de un grupo heterogéneo de autoras cuyas temáticas abarcan la relación con el cuerpo, la sexualidad y la maternidad, y nos revela su labor como co-fundadora y coeditora de la revista Brígida en la promoción de las obras de autoras chilenas y latinoamericanas.

In this interview, the Chilean graphic artist Marcela Trujillo describes her personal trajectory as a graphic artist, underlining her passion for figurative painting as well as the influence of women-authored North American autobiographical underground comics on her own artistic formation. In her brief panorama of contemporary Latin American graphic narratives, she highlights the presence of a growing number of women authors who are renewing this medium. In a conversation with Marina Bettaglio, Trujillo describes the most innovative aspects of a heterogenous group of female authors whose work centers on the body, sexuality, and motherhood. She discusses her work as co-founder and co-editor of the magazine Brígida in promoting the works of Chilean and Latin American graphic artists.

MARINA BETTAGLIO: Nos gustaría que nos hablaras de tu trayectoria como dibujante y como autora reconocida en el ámbito de la novela gráfica.

MALIKI: Como ya he contado en otras ocasiones, mi pasión por la pintura, por el dibujo, por la expresión artística y gráfica se remontan a mi infancia. De niña me encantaba dibujar, era algo que me hacía feliz. Pasaba mis ratos libres dibujando. En mi casa todos leíamos una variedad de cómics - $L a$ pequeña Lulú, Pato Donald, Tío Rico, Tribilín, Periquita, Archie y Condorito y a veces los comentábamos en las comidas. No sé si mi pasión por el cómic viene de allí, de aquellas lecturas y de los dibujos a los que le ponía globos de texto. Pero lo cierto es que estudié una carrera de Bellas Artes en Chile y

REVISTA CANADIENSE DE ESTUDIOS HISPÁNICOS 43.I (OTOÑO 2OI8) 
luego me formé en Nueva York, ciudad en la que viví siete años. Fue una etapa fundamental para mí porque allí descubrí el cómic underground femenino y autobiográfico, en particular el volumen Twisted Sisters (1991). Allí aparecen los cómics de Julie Doucet, Phoebe Gloeckner y Debbie Dreschler, que muestran una serie de temáticas íntimas tratadas desde un prisma irónico y desmitificador que desafía la lógica patriarcal, según la cual las mujeres en el cómic son sobre todo objetos sexuales. Fue entonces cuando me di cuenta de que la narrativa gráfica podía ser el vehículo a través del cual reivindicar una serie de temas invisibilizados. Como artista formada en la pintura, me acerqué al mundo del cómic con unas herramientas gráficas que me permitieron expresar mis vivencias, desafiar los estereotipos, salirme de las convenciones y afrontar temas tabú. A través del personaje de Maliki 4 Ojos pude mostrar los condicionantes culturales a los que se enfrentan las mujeres en una sociedad patriarcal, marcada por el catolicismo, los imperativos de género y las expectativas sociales que nos transforman en seres callados, sufridores, invisibles.

MARINA BETTAGLIO: ¿Podrías trazar un panorama de la narrativa gráfica latinoamericana de autoría femenina? Empecemos por los temas. ¿Qué temática se evidencia en la producción de las nuevas artistas gráficas?

MALIKI: Hay un espectro de temas que socialmente se asocian a las mujeres y que estereotipan sus roles, como el yugo de la belleza física, la maternidad en todas sus dimensiones, la reapropiación del cuerpo, la sexualidad, el inconsciente, el amor, el sufrimiento por el desamor, los celos, el abandono, el abuso, la familia, la idealización del hombre, lo doméstico, etc. Muchos de esos temas aparecen en sus trabajos, pero sobre todo surgen nuevos temas relacionados con la búsqueda de significados emocionales en las cosas; ver la realidad con un filtro instintivo; el caos, el juego, lo circular; las divagaciones poéticas a partir de la música, la mitología personal; temas que se relacionan con el mundo femenino íntimo, profundo, no social, más bien interno, inconsciente y emocional. Yo creo que las mujeres hemos sido víctimas por tantos años de las exigencias sociales para servir, obedecer y vivir para otros que el redescubrir nuestro cuerpo, nuestras ideas y gustos, incluso la experiencia sensorial, es absolutamente lógico. La libertad que supone romper con el patriarcado y todo lo que implica ese gran cambio nos hace quedar desnudas frente a nosotras mismas y reconocer qué es lo que realmente nos gusta o disgusta. Por ejemplo, si queremos ser madres y cómo queremos serlo, si realmente necesitamos un hombre al lado para formar una familia o la formamos sólo con hijas, si queremos o no formar una familia, si lo que nos gusta es dedicarnos a formarnos como 
profesionales y no nos interesa ser madres o si queremos hacer las dos cosas a la vez; si lo que más nos importa y nos llena de deseos es hacer algo que no es lo que los demás esperan de una, etc. Poder darnos cuenta de eso y atrevernos a ser personas integrales como lo han sido los hombres siempre implica mucho trabajo por nuestra parte y creo que estas inquietudes aparecen en los cómics. No hay tanto discurso político ni opiniones racionales o morales. Los temas son mucho más abstractos y personales, son reflexiones de cómo descubrimos el mundo a nuestra manera, con humor, poesía, incluso ironía, pero no hay un espíritu de rebelión y choque.

En la actualidad, Pati Aguilera, Sol Díaz, la periodista Isabel Molina y yo como editoras, más tres dibujantes, producimos la revista de cómics hechos por mujeres llamada Brígida, que ya cuenta con cinco números. En cada número, invitamos a 11 autoras chilenas y latinoamericanas a crear un cómic de i o 2 páginas sin un tema específico, precisamente para que ellas propongan los que más les interesen.

MARINA BETTAGLIO: Uno de los temas que han salido a relucir, además de la sexualidad es la maternidad, tema tradicionalmente silenciado. ¿Cómo influyen los mitos de la maternidad en tus obras y en las de otras autoras?

MALIKI: La maternidad ha sido para las mujeres la razón de vivir, la meta final de la existencia y la base en la que se conforma la familia, el núcleo fundamental de la sociedad como la conocemos ahora, la sociedad de consumo. Por lo tanto, enfrentar ese tema desde un punto de vista honesto y emocional puede ser a veces muy complejo para nuestra imagen. Y no es hablar de imagen. La imagen es la gran cárcel de nuestro género. Sentirse una "mala madre" implica la sensación de fracaso que opaca toda la vida, aunque una tenga la mejor profesión del mundo o haya logrado metas impensables. Si eres mala madre, todo se pudre; es como un hedor que envuelve el alma. Cuando las autoras hablamos de la maternidad desde el otro lado - el que no está permitido - cuando decimos que nunca quisimos tener hijos, que criar hijos es terrible porque simplemente desaparecimos ${ }^{2}$ o que jamás tendremos hijos porque queremos vivir la vida sin esa responsabilidad, tendemos a filtrarlo con un poco de humor y buena onda para no parecer brujas indolentes. La culpa asociada a cumplir mal el rol de madre es inherente a la cultura católica, donde la imagen de la mujer es la madre de Dios, una mujer con su pelo y cuerpo completamente tapados, llorando y sufriendo por la muerte de su hijo. Una mujer que es elegida: ella no elije nada. Dios elije por ella. Una mujer que está en el suelo o que está parada rodeada de ángeles y que nunca tuvo ni tendrá sexo. Es decir, una niña pequeña, que depende de sus padres, sin autonomía y protegida del 
deseo sexual de los hombres. María no es precisamente una madre. La madre la tenemos que inventar nosotras y siempre se nos desborda. La maternidad es un rol muy animal, pienso yo, según mi experiencia y lo que he visto, y es difícil asociarlo a lo salvaje, al instinto, a las fuerzas más dramáticas de la existencia, el lado oscuro, porque se asocia socialmente y "consumidoramente" como un acto de belleza y amor extremo, cuando en realidad es un estado de alerta y angustia constante que requiere que nos convirtamos en fieras, como la osa madre que ataca a quien se acerca a su bebé oso. Derribar el mito de la maternidad hermosa y amable es un tema que cuesta - a mí me cuesta porque la culpa que implica frente a mis hijas, que amo más que nada en el mundo - se vuelve contra mí y me impide ser honesta. Yo no puedo hablar por las demás mujeres, no me corresponde, menos en ese tema. Pero creo que el cómic fue mi salvación para enfrentar la maternidad. Sin el arte y sin el cómic, me habría desarmado entera. Yo creo que el festival de hormonas al que uno entra cuando está embarazada, amamantando y criando, es la gran metamorfosis de la humanidad. Las mujeres que somos madres y que vivimos esa experiencia no somos mejores mujeres o seres iluminados, somos personas convertidas en un cóctel de hormonas al que baten y así nos transformamos en otras durante varios años. Después volvemos a sentirnos como antes pero estamos a cargo de un hijo, la vida se hace más compleja y una deja de ser el centro del universo para siempre. No sé si eso es lo mejor que te puede pasar. Quizás para la supervivencia de la humanidad y para que no se acabe el mundo puede ser. Pero, en términos personales, no. La maternidad es un tema eterno para las mujeres.

MARINA BETTAGLIO: ¿Qué importancia tiene el contexto socio-cultural y económico en la narrativa gráfica de autoría femenina?

MALIKI: Siempre influye, sobre todo en países como Chile, donde no hay un estado benefactor y protector de la educación de todos, donde la educación y la salud son privilegios de quienes pueden pagarlos. La práctica de hacer cómics como un trabajo remunerado no existe en Chile. Las autoras generalmente viven de hacer ilustraciones comerciales bien remuneradas y de la docencia, no de los derechos de autor de sus libros. Eso para empezar. Segundo, hay un número cada vez mayor de autoras que solo han publicado fanzines (una cultura underground) y autoras de clases sociales más privilegiadas, pero ambas transitan por temas que van desde la crítica social hasta testimonios de sus universos personales. Aunque la realidad social de cada autora siempre permea en los temas de sus cómics, hay un abanico muy diverso de puntos de vista. Se organizan colectivos, eventos 
comunitarios, festivales, mesas redondas y talleres donde confluyen distintos tipos de autoras de distintas generaciones, clases sociales, gustos, ideas políticas y estilos.

MARINA BETTAGLIO: ¿Cuánto han contribuido las nuevas tecnologías a la difusión de la obra de las autoras?

MALIKI: Mucho. YouTube, Instagram, Facebook, el blog, han sido clave para el desarrollo y la difusión del trabajo gráfico de las autoras. Yo tengo una teoría que desarrollé porque vengo del mundo de las Bellas Artes. Estudié, pinté y expuse por más de una década antes de publicar mis propios cómics (en I989, publiqué cómics, pero solo los dibujé -- los guiones eran de un amigo), y muchas de mis amigas artistas habían elegido la carrera de arte porque dibujaban de chicas, como yo. Pero en los 9o, el arte conceptual, las instalaciones y el videoarte irrumpieron y barrieron con la idea de que el dibujo y la pintura figurativa eran parte del mundo de las artes visuales, y se empezaron a ver con desdén. Hay incluso un cómic de Daniel Clowes donde cuenta su experiencia como alumno de una escuela de arte y lo frustrante que fue vivirla. Se titula Art School Confidential (2006), sobre la cual hicieron una película después. Cuando la ilustración empezó a ser sinónimo de mediocre para el mundo del arte, las personas, hombres y mujeres, que amaban dibujar se frustraron y empezaron a mirar el cómic con ganas. El cómic fue lo que me devolvió el alma al cuerpo. El arte conceptual es tan racional y planificado, tan masculino, que pasa sobre el dibujo, lo usa solo como medio para explicar algo. Entonces yo creo que lo que me pasó a mí le debe haber pasado a muchas personas. Yo amo dibujar, y, siendo pintora, no dibujaba mucho. Los temas figurativos eran siempre motivo de desconfianza en la mirada del crítico, y con razón: en un mundo donde ya todo se hizo ¿para qué seguir pintando lo mismo? Es mejor cambiar y ser original. El cómic como arte apareció después de que el cómic underground se convirtiera en cómic independiente, pasando por la vereda del frente del cómic de superhéroe, producido a modo de industria con equipos de escritores, dibujantes y coloristas que trabajaban en una fábrica de salchichas. La revista Raw y la revista Weirdo paralelamente nutrieron ese amor por el dibujo que muchos sienten. La necesidad de dibujar es universal. Y yo creo que, después de la fiebre del 3D y de la imagen digitalizada al extremo, no podía ocurrir sino que diéramos la vuelta, es decir, volver al origen, al lápiz, al plumón, a la hoja, al material análogo. Y por eso, sumándose a la moda del arte conceptual, el cómic fue un respiro para muchos y muchas: el lugar donde se puede dibujar y se pueden contar historias con dibujos. Luego de eso, vino el tema de publicarlos y sucedió a 
la par, porque la Internet llegó a mediados de los 90 así es que los dibujantes no solo tenían que depender de las editoriales, también podían publicar ellos mismos sus dibujos. Y eso hicieron. Ahora incluso hay autoras que utilizan los medios audiovisuales para promocionar sus dibujos mientras promocionan sus imágenes de artistas independientes. Como Frannerd, por ejemplo, quien vive actualmente en Nueva York y mantiene un diario en video semanal donde uno puede visitar museos con ella, ir al parque, al correo, estar en su departamento con sus gatos, todo porque, con su cámara en la mano, es posible filmar el presente. Los videos los edita con música y tiene además un sistema de autofinanciamiento con Patreon, donde sus fans le depositan dinero mensualmente para que ella pueda comprar materiales y filmar su vida de artista dibujante ilustradora joven, sin hijos y en el extranjero (también vivió en Alemania y en Inglaterra). Muchas autoras dependen de las redes sociales para vender sus ilustraciones, para difundir sus eventos, talleres y charlas, y para encontrar una comunidad de ilustradoras e historietistas con quienes compartir sus experiencias y referentes.

MARINA BETTAGLIO: ¿Qué relación mantienen las autoras con la industria editorial? ¿Se venden sus libros en las tiendas de cómic o hay que buscarlos en librerías especializadas? ¿Cómo se abren camino en un mundo tan dominado por la mirada masculina?

MALIKI: Las editoriales que publican autoras distribuyen sus libros en librerías de libros, no necesariamente en librerías especializadas, que tampoco hay muchas, (supongo que me preguntas por Chile). Hay muchas editoras mujeres también, lo cual ayuda a que se expanda el ojo editorial y se deje de ver a los hombres como potenciales autores y se empiece a ver a las mujeres como autoras válidas. Si bien el público estaba cargado de testosterona cuando se trataba de vender cómic, ahora es diferente. Hay autoras que son leídas mayoritariamente por mujeres y por mujeres que nunca antes habían leído un cómic pero que ahora lo hacen regularmente. El cómic hecho por mujeres ha creado un público femenino nuevo, que no es exclusivo del comic femenino, sino que además se interesa en el cómic hecho por hombres. A las mujeres no nos cuesta ser unisex, porque siempre lo hemos tenido que ser. En cambio, a los hombres les cuesta comprar un libro hecho por una mujer que hable un tema de mujeres, de alguna manera ellos tienden a separar los temas por género, y no se les hace fácil consumir temas que son socialmente vistos como femeninos, porque chocan con sus creencias patriarcales que les dicen que las mujeres son menos que ellos, 
son más débiles, o son menos inteligentes o locas, aunque la maternidad, el divorcio o el abuso sean temas que les incumben a ellos directamente.

MARINA BETTAGLIO: ¿Qué futuro le ves al cómic latinoamericano en general y en particular al de mujeres? ¿Qué consejos le darías a la nueva generación de dibujantes, hombres y mujeres?

MALIKI: Ya quisiera tener la capacidad de ver el futuro, pero no puedo. Nunca me resulta ni con mis propios planes. Lo único que tengo claro es que, cuando yo volví a Chile en 2007, no había editoriales especializadas en cómic y las editoriales clásicas tampoco los publicaban; no había librerías donde vendieran cómics independientes ni galerías que expusieran originales de cómics. Todo eso ocurrió en el transcurso de diez años y en un nivel mucho más artesanal y humilde que en EEUU, Canadá y Europa. Mucho más humilde, pero ocurrió. Las cosas que suceden en el Primer Mundo siempre terminan ocurriendo en el Tercer Mundo años más tarde y en versiones acomodadas a nuestras realidades económicas, políticas y sociales. Si el cómic femenino en EEUU, Canadá y Europa se hace cada vez más masivo y su calidad va en aumento, y si la cantidad de autoras se está multiplicando y ellas empiezan a ganar premios que tradicionalmente ganaban los hombres, si empiezan a aparecer editoriales de mujeres y más editoras están a la cabeza de las grandes casas editoriales, entonces acá sucederá también, pero en menor escala. Es lo único que puedo predecir, porque es lo que he visto que ocurre.

También los cambios suceden a veces porque las malas prácticas machistas llegan a niveles de alerta roja y nosotras perdemos la paciencia. Nos aburrimos de que los hombres organizaran los eventos de cómic e invitaran a las mujeres a mesas de cómic solo de mujeres, como si fuéramos rarezas extras con las que ellos no se mezclan. Siempre accedíamos a participar y como había pocas mujeres publicando cómics, terminábamos yendo siempre las mismas. La pregunta era ¿y por qué no hacemos nosotras nuestro propio evento, nuestra propia comunidad? ¿Porqué tenemos que esperar que nos inviten ellos? ¿Porqué nos da miedo lanzarnos a armar nosotras una publicación o un festival - o lo que sea - sin tener que esperar que ellos lo ideen o lo manejen? ¿Porque esperamos que los hombres hagan la historia y no nosotras?

Y la respuesta fue primeramente el podcast La Polola 3 (Sol Díaz y yo) donde entrevistamos a muchas dibujantes y autoras chilenas y latinoamericanas (también a hombres dibujantes y a personas de otras profesiones que nosotras admiramos), y después de dos años, la segunda 
respuesta fue Revista Brígida, donde hemos publicado a noventa autoras y tenemos una lista que crece día a día.

La audiencia que creamos es nueva porque muchas mujeres que leen Brígida nunca han leído un cómic antes, y no es raro, ya que muchos cómics eran hechos por hombres y hablaban de sus realidades donde la mujer es un objeto de su placer o una víctima de su poder. Nuestra audiencia es nueva y eso es importante cuando se trata de renovar. También hay muchas dibujantes que nunca habían dibujado un cómic pero sí habían ilustrado para libros infantiles o para proyectos comerciales. Ellas también están entrando a un nuevo mundo y es más fácil que se queden dentro si el ambiente es diverso, inclusivo y hay otras personas que también son principiantes, donde la libertad de temas y de técnicas es una prioridad; donde la organización es horizontal y no piramidal. Creo que los nuevos movimientos feministas han evolucionado mucho. Ya no es solo rabia lo que nos mueve, es convicción de que juntas es la única manera que podemos presionar y exigir nuestros derechos. Nosotras, como dibujantes y autoras, tenemos nuestras herramientas gráficas y literarias para contar nuestras historias, las que estamos acostumbradas a callar, ocultar y avergonzarnos. Nos cuesta mucho compartir nuestras experiencias de dolor porque no queremos sentirnos víctimas y no queremos ser vulnerables, ya que sabemos que somos presa fácil del machismo si somos débiles. Y necesitamos compartir esas historias porque una de cada tres mujeres han sufrido, sufren o sufrirán abuso sexual en su vida, porque la historia de la mujer está escrita con ninguneos, pisoteos, falta de reconocimiento y exigencias sin valor ni monetario ni social. Las mujeres tenemos grabado a fuego en nuestros cuerpos lo que nuestros ancestros femeninos han sufrido por siglos: las opresiones, las injusticias, los abusos y todos los malos tratos, pero a la vez tenemos un dictamen tan fuerte del deber ser (lindas, flacas, tímidas, amables, cariñosas, generosas, acogedoras, perfectas) que se nos va mucha energía en tratar de estar a la altura de las expectativas de otros y nos cuesta mucho darnos cuenta de las propias.

\section{NOTAS}

I Marcela Trujillo es una artista gráfica chilena cuya trayectoria incluye la pintura, el cómic, las novelas gráficas y la ilustración, actividades que compagina con la labor docente que ha desarrollado en el ámbito universitario y en talleres dedicados a un público infantil. Conocida e identificada con su alter ego, Maliki 4 Ojos, personaje que protagoniza sus obras de carácter más marcadamente autobiográfico, Marcela Trujillo ha publicado Maliki en tinta 
china, Diario íntimo de Maliki 4 Ojos (2011), El diario iluminado de Maliki 4 Ojos (20II) y más recientemente Ídolo (20I7). Con la psicóloga Carolina Lama ha colaborado en la elaboración de Quiero ser flaca y feliz. Método visual para bajar de peso (2015). Sobre la trayectoria artística de Marcela Trujillo, se remite al artículo de Vilma Navarro Daniels "Dibujar para subvertir: cuerpo, género y poder en las crónicas y los diarios gráficos de Marcela Trujillo (o Maliki 4 0jos)", en este volumen. Para más información sobre la Revista Brígida, ver https://grafitoediciones.wordpress.com/publicaciones/revista-brigida/.

2 Marcela Trujillo resalta el aspecto totalizante de la identidad maternal que hace "desaparecer" a la mujer, ya que su individualidad queda subsumida al rol materno.

3 El podcast $L a$ Polola se emite con periodicidad variable desde el 29 de junio de 2016.

OBRAS CITADAS

CLowes, DAnie L. Art School Confidential. Seattle: Fantagraphics, 2005.

CRUMB, ROBERT, PETER BAgGe y ALINE KOMINSKy-CRUMB. Weirdo. (I98I-I993).

Last Gasp. S. pag. Web.

No o m I n, D I A E. Twisted Sisters: A Collection of Bad Girl Art. New York: Penguin Books, I991.

SPIEgELMAn, ART, Y FRAn Ç OISE Mouly. Raw. New York: Raw Books \& Graphics (1980-1986); Penguin Books (1989-1991).

trujillo, marcela (maliki). El diario iluminado de Maliki 4 Ojos. Santiago, Chile: Ocho Libros Editores, 2013.

-. El diario íntimo de Maliki 4 Ojos. Santiago, Chile: RIL Editores, 20 II.

-. Maliki en tinta china. Obras incompletas. Santiago, Chile: Ocho Libros Editores, 2013.

TRUJillo, marcela (MAliki), Sol díaz, pati aguilera e isabel molina. Revista Brígida (2017-2018). Grafito Ediciones, Wordpress. S. pag. Web. trujillo, marcela (maliki), y sol díaz. "La Polola: Podcast de cómic femenino." Santiago, Chile: Soundcloud. S. pag. Web. 